\title{
Assessment of Soil Moisture Data Requirements by the Potential SMAP Data User Community: Review of SMAP Mission User Community
}

\author{
Molly E. Brown and Vanessa M. Escobar
}

\begin{abstract}
NASA's Soil Moisture Active and Passive (SMAP) mission is planned for launch in October 2014 and will provide global measurements of soil moisture and freeze/thaw state. The project is driven by both basic research and applied science goals. Understanding how application driven end-users will apply SMAP data, prior to the satellite's launch, is an important goal of NASA's applied science program and SMAP mission success. Because SMAP data are unique, there are no direct proxy datasets that can be used in research and operational studies to determine how the data will interact with existing processes. The objective of this study is to solicit data requirements, accuracy needs, and current understanding of the SMAP mission from the potential user community. This study showed that the data to be provided by the SMAP mission did substantially meet the user community needs. Although there was a broad distribution of requirements stated, the SMAP mission fit within these requirements.
\end{abstract}

Index Terms-Agriculture, applications, hydrology, remote sensing, soil moisture.

\section{INTRODUCTION}

$\mathbf{N}$ ASA provides the majority of free, comprehensive, earth science observation data available in the world. The hallmark of NASA programs is the integration of observations into consistent global datasets and models to support scientific research programs, through research and use of operational satellite, airborne and surface-based observation networks [1]. Recently, budget shortfalls, launch failures, cost growth, and changes in mission design and scope have left NASA facing a rapid decline in capability in earth observation [2]. Because satellite missions take a long time to develop, engaging with potential data users during the early stages of mission development is the best way to ensure that new observations meet the most urgent demands of users and have the broadest impact.

NASA's Soil Moisture Active Passive (SMAP) mission is planned for launch in October 2014 and will provide global measurements of surface (top $5 \mathrm{~cm}$ ) soil moisture and its freeze/thaw state [3]. SMAP is an $L$-band combined radar-radiometer satellite mission expected to satisfy a broad range of

Manuscript received November 14, 2012; revised February 11, 2013; accepted April 28, 2013.

The authors are with the Biospheric Sciences Branch, Code 618, NASA Goddard Space Flight Center, Greenbelt, MD 20171 USA (e-mail: Molly.brown@nasa.gov; Vanessa.escobar@nasa.gov).

Color versions of one or more of the figures in this paper are available online at http://ieeexplore.ieee.org.

Digital Object Identifier 10.1109/JSTARS.2013.2261473 applications. Microwave soil moisture research has a rich heritage stemming back over 20 years suggesting that the optimal frequency for remote sensing soil moisture is $L$-band (Crosson, et al., 2010). $L$-band backscatter is less sensitive to the crop canopy (Balenzano, et al. 2011), has a deeper penetration depth and reduced sensitivity to surface roughness (Crosson, et al. 2010) and a greater sensitivity to the vegetation water content than $\mathrm{C}$ band.

After launch, the mission will provide high quality, daily, 9-km resolution global soil moisture data, which is expected to have both high science and applications value (Table I). These measurements will be used to enhance the understanding of processes that link the water, energy and carbon cycles, and to extend the capabilities of weather and climate prediction models [4]. As part of its development, SMAP has funded an active applications program that seeks to engage the science data user community early in the mission design and development processes of the SMAP mission. Providing actionable and user friendly data to decision makers has become a priority as world leaders try to understand and communicate about earth system, specifically issues that surround climate and climate change. Applications have quickly become an integral part in converting satellite data into knowledge that can be used to inform policy and enhance decision-making processes [5]. Thus, clarification to how we define applications is important when communicating efforts for improving the applications of data for societal benefits:

- applications are defined as innovative uses of mission data products in decision-making activities for societal benefit;

- applications research will provide fundamental knowledge of how mission data products can be scaled and integrated into users' policy, business, and management activities to improve decision-making efforts.

The SMAP applications program [6] uses the mission's prelaunch test data to engage with a broad range of environmental monitoring and decision making systems ranging from drought and flood guidance to disease risk assessment and national security during the mission development phases for SMAP (four years prior to launch). These efforts are designed to increase the ingestion of SMAP data into critical processes and research, improving its impact on society once the satellite has been launched and is functioning. Understanding how users intend to apply SMAP soil moisture data, prior to the satellite's launch is an important component of the SMAP Applied Sciences activity and has become part of the way NASA will measure the mission's success. 
TABLE I

SMAP Mission Products TABle, ACCURACIES AND LATENCY

\begin{tabular}{|c|c|c|c|c|}
\hline Product & Description & $\begin{array}{c}\text { Gridding } \\
\text { (Resolution) } \\
\end{array}$ & Latency* & \\
\hline L1A_TB & Radiometer Data in Time-Order & - & $12 \mathrm{hrs}$ & \multirow{6}{*}{ Instrument Data } \\
\hline L1A_S0 & Radar Data in Time-Order & - & 12 hrs & \\
\hline L1B_TB & Radiometer $T_{B}$ in Time-Order & $(36 \times 47 \mathrm{~km})$ & $12 \mathrm{hrs}$ & \\
\hline L1B_S0_LoRes & Low Resolution Radar $\sigma_{\mathrm{o}}$ in Time-Order & $(5 \times 30 \mathrm{~km})$ & $12 \mathrm{hrs}$ & \\
\hline L1C_SO_HiRes & High Resolution Radar $\sigma_{o}$ in Half-Orbits & $\begin{array}{c}1 \mathrm{~km} \\
(1-3 \mathrm{~km})^{\star \star \star}\end{array}$ & $12 \mathrm{hrs}$ & \\
\hline L1C_TB & Radiometer $T_{B}$ in Half-Orbits & $36 \mathrm{~km}$ & $12 \mathrm{hrs}$ & \\
\hline L2_SM_A ${ }^{* *}$ & Soil Moisture (Radar) & $3 \mathrm{~km}$ & $24 \mathrm{hrs}$ & \multirow{3}{*}{$\begin{array}{l}\text { Science Data } \\
\text { (Half-Orbit) }\end{array}$} \\
\hline L2_SM_P & Soil Moisture (Radiometer) & $36 \mathrm{~km}$ & $24 \mathrm{hrs}$ & \\
\hline L2_SM_AP & Soil Moisture (Radar + Radiometer) & $9 \mathrm{~km}$ & $24 \mathrm{hrs}$ & \\
\hline L3_FT_A & Freeze/Thaw State (Radar) & $3 \mathrm{~km}$ & $50 \mathrm{hrs}$ & \multirow{4}{*}{$\begin{array}{c}\text { Science Data } \\
\text { (Daily Composite) }\end{array}$} \\
\hline L3_SM_A ${ }^{* *}$ & Soil Moisture (Radar) & $3 \mathrm{~km}$ & $50 \mathrm{hrs}$ & \\
\hline L3_SM_P & Soil Moisture (Radiometer) & $36 \mathrm{~km}$ & 50 hrs & \\
\hline L3_SM_AP & Soil Moisture (Radar + Radiometer) & $9 \mathrm{~km}$ & $50 \mathrm{hrs}$ & \\
\hline L4_SM & Soil Moisture (Surface and Root Zone ) & $9 \mathrm{~km}$ & 7 days & \multirow{2}{*}{$\begin{array}{c}\text { Science } \\
\text { Value-Added }\end{array}$} \\
\hline L4_C & Carbon Net Ecosystem Exchange (NEE) & $9 \mathrm{~km}$ & 14 days & \\
\hline
\end{tabular}

* The SMAP Project will make a best effort to reduce the data latencies beyond those shown in this table

${ }^{\star *}$ Research product with possible reduced accuracy

*** Over Outer $70 \%$ of Swath

This paper focuses on understanding how individuals and organizations assess and plan for use of satellite mission data before launch. Because SMAP will have such a broad field for applications, there will be a need for users to calibrate the satellite data to their relevant spatial scale. The remote sensing estimate is only a coarse-resolution representation of a filed map. An early understanding of user requirements will help in ensuring that SMAP observations are used at different thematic scales.

The objective of this study is to solicit data requirements, accuracy needs and a current understanding of the SMAP mission from the user community and relay that information back to the mission scientists. We present an analysis of an online professional review of expert end users and earth science researchers associated with the SMAP applications program. The review focuses on eliciting how pre-launch activities and research is being conducted in organizations, and identifying the boarder communities who have participated in pre-launch applications meetings and briefings. We use experiences from the Famine Early Warning Systems Network (FEWS NET)'s evaluation of its user community [7] where a professional review was used to collect information about remote sensing requirements from the FEWS NET community of users.

\section{Professional Review}

Soil moisture end users and experts who have volunteered to take part in the SMAP Applications Working Group responded to a SMAP mission-specific professional review in the form of an online questionnaire to quantify satellite remote sensing requirements. We term this questionnaire as a professional review because it was not intended to engage the broader Earth science community or public, but sought the opinion of individuals who have requested to be involved in the mission and have participated in pre-launch SMAP application activities. The goal of the review was not only to improve the end user's understanding of SMAP applications activities but also to comprehend and facilitate the requirements from SMAP user communities back to the SMAP mission. The subject community included over 200 SMAP applications working group members (AppWG) [8] representing a network of disciplines in hydrology, agriculture, hazards, weather, climate, and health. The review was subdivided into three broad sections: user information, user requirements, and user research applications.

The review comprised questions on respondent characteristics, including experience and training, years of experience, whether the respondent was a manager or decision maker, and their disciplinary affiliation. In addition, we asked whether the individual participated in policy making, planning for environmental hazards, monitoring of agriculture or other natural resource, or conducted research.

The questions regarding user requirements focused on determining the environmental variables, spatial scale, spatial extent, temporal frequency, product latency, and most useful prediction time scale of SMAP data products. The focus was on determining what was optimal for the user compared to what SMAP actually plans to produce. Effort was made to elicit details on accuracy and precision of the need for soil moisture products by the community engaged with the SMAP mission before launch.

Finally, there were questions on the respondent's research and the applications they will incorporate SMAP data into. This included asking whether the respondent currently used other soil moisture datasets in their activities and whether they would need 
TABLE II

QUESTIONS INCLUDED IN THE REVIEW

1. Are you a professional or scientist with training, expertise or experience related to deriving or modeling environmental information?

2. Are you a manager or decision maker whose organization is interested in soil moisture or other environmental observations for their systems or processes?

3. Please provide your discipline or area of expertise.

4. Of the following thematic groups, which is your work most closely associated with?

5. Which tier best describes the level at which you make or influence decisions using remote sensing information?

6. How many years have you been professionally engaged with environmentally related work?

7. What is the highest level of training you have received in the following areas?

8. Are you involved in the following types of action (either directly or by influence)?

9. How valuable are the following environmental variables to your analysis?

10. SPATIAL RESOLUTION: What spatial scale is most important to your analysis? In other words, what is the finest level of spatial detail that is important in your analysis? If your analysis requires information from multiple spatial scales, please check as many as apply.

11. Continuing from question 10, Can you relate your optimal spatial scale to an optimal pixel resolution, please specify each in meters. (pixel refers to a single grid cell in a raster map)

12. SPATIAL EXTENT or COVERAGE: What area of coverage is best for your analysis? If your analysis requires information at multiple levels of coverage, please check as many as apply.

13. TEMPORAL FREQUENCY: What temporal scale is most important to your analysis? (how often do the data need to be updated) If your analysis requires information at multiple temporal scales, please check as many as apply.

14. LATENCY: For purposes of your analysis, how timely must information arrive to have a positive impact?

15. PREDICTION TIME SCALE: How far in advance do you need to know risk indicators to provide useful environmental analysis?

16. Please comment regarding the applications that drive your spatial and temporal requirements.

17. Have you attended a SMAP applications workshop or meeting describing the data products and algorithms?

18. Do you use SMAP test data or use a proxy dataset in your research?

19. How do you integrate these datasets into your process, analysis or research?

20. Please indicate if one or more spatio-temporal requirements for soil moisture differ from the genera requirements you detailed Section 4.

21. For your analysis, how valuable are the following soil moisture measurement historical time series to your early warning analysis? Historical information provides information on soil moisture condition during previous years.

22. For your analysis, what level of accuracy is important in the estimation of a soil moisture (as measured or predicted for a 10-day period)?

23. Which do you believe are most useful to decision makers, absolute or relative soil moisture anomalies? A relative soil moisture anomaly is expressed in percent of normal, whereas an absolute anomaly is expressed in meter cubed water per meter cubed of soil.

24. Please indicate if one or more spatio-temporal requirements for freeze/thaw information differ from the general requirements you detailed in the Section 4.

25 . For your analysis, how valuable are the following freeze/thaw measurement historical time series to your analysis? Historical information provides information on soil moisture conditions during previous years

26. For your analysis, what level of accuracy is important in the estimation of a freeze/thaw historical product?

27. Which do you believe are most useful to decision makers, absolute or relative freeze/thaw anomalies?

28. If you have additional comments on your needs or requirements for soil moisture or freeze/thaw data, please add them here.

information on past conditions (historical data) upon launch of the sensor in order to understand the difference between current and 'normal' soil moisture conditions. Similar questions were also asked with regard to the soil freeze/thaw state and how these products are likely to be used.

The SMAP professional review was made available to the community in February 2012 and responses were accepted for this research through the end of April 2012. Of the 240 invitees, 63 participated in the professional review. Ninety-one percent of the reviewers had over seven years' experience in their occupational field. In this paper, we assess the users responses to understand the perceived benefits to pre-launch efforts and define areas were the connection between science development and user applications could continue to improve and further benefit the mission. Table II provides the questions asked during the online review.

\section{Of the following thematic groups, which is your work most} closely associated with?

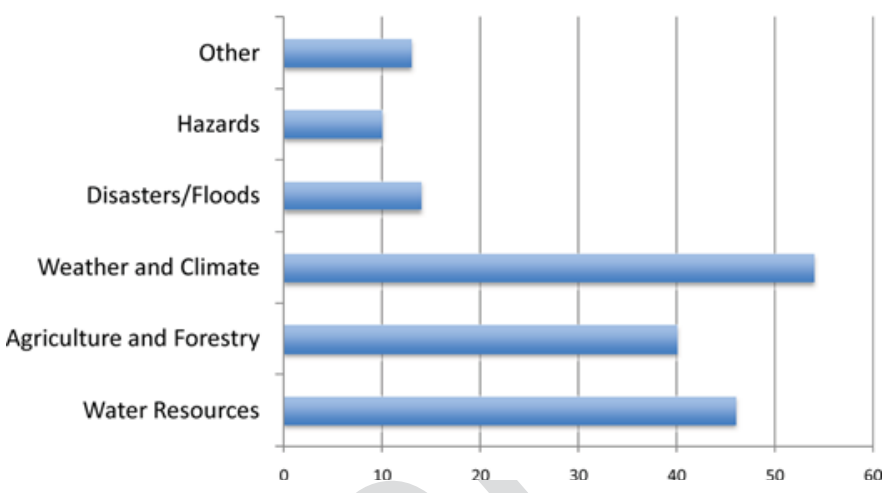

Fig. 1. Responses to review question regarding thematic group affiliation.

\section{RESULTS AND DISCUSSION}

Our major findings are that the user community will be able to use the SMAP data with its current specifications in spatial, temporal, and delay after launch in the application disciplines of hydrology, agriculture, hazards, weather, climate, and health.

\section{A. SMAP Pre-Launch User Community}

The diversity of the SMAP user community and the various fields of application were quantified through the use of this review. Of the 63 respondents, $45 \%$ identified themselves as managers or decision makers whose organization is interested in soil moisture or other environmental observations for their systems or processes, leaving $55 \%$ of the respondent associated with research, processing, or product development. Thematic groups requiring soil moisture for their research but limited (in terms of access due to format challenges, latency, or awareness of data availability) were also identified through this process. Dominant areas for applying SMAP data products were distinguished by thematic disciplines needing more user engagement. When users were asked to self-identify their area or discipline of expertise, the fields ranged from hydrology to numerical modeling.

Nearly all respondents (98\%) identified themselves as "science data users" involved with creating or analyzing scientific products. Of the disciplines identified, remote sensing was the strongest making up $34 \%$ of the respondent population, followed by hydrology (18\%) and modeling (13\%) (Fig. 1). The remaining categories represented less than $7 \%$ of the respondent community. When users were later asked to fit their disciplines into one of five mission-specific thematic disciplines, responders associated themselves most with weather and climate $(54 \%)$ and water resource $(46 \%)$ as dominant thematic fields. Agriculture was the third most represented category with $40 \%$ of the participants responding. "Disasters," "hazards," and "other" each made up $20 \%$ or less of the participants responses.

Reviewers were given the option to specify their thematic discipline in the "other" category if the option was not represented in the selections given. When analyzed, "other" was composed of emergency and hazard response groups, such as risk development, fire danger, flooding response, emergency management, and military transportation. These categories represent a highly "operational" branch of knowledge that possess different data 


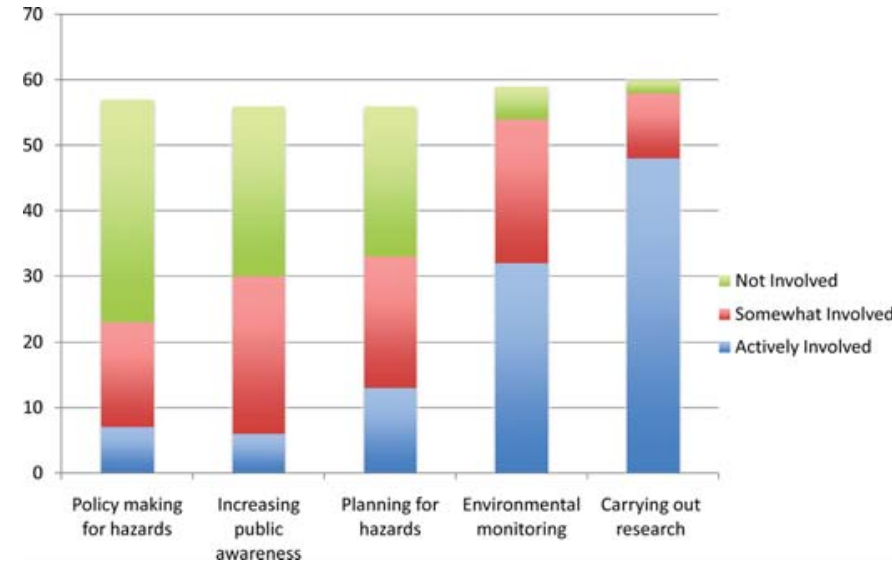

Fig. 2. Answers selected for the question: Are you involved with the following types of action (either directly or by influence)?

requirements (format, delivery, and data access) than the science and research dominant fields represented in this study.

When assessing the responses of the review, we identified gaps between the fields of scientific research, operation and those of involved in public policy and decision-making, existing within the SMAP user community (Fig. 1). Eighty percent of the reviewers were involved in carrying out soil moisture related research (Fig. 2). However, 60\% of the participants stated that they were not involved in policy applications pertaining to hazard mitigation. This implies that flood planning products and drought-monitoring products (that require soil moisture data) are poorly connected to policy decision-making sectors and are still only research oriented. Over the next few years, the SMAP applications program will work to increase the visibility and participation of policy and decision-making communities who use satellite data in the pre-launch planning and activities to ensure the maximum use of the product after launch.

Hazard response, policy, and other decision-making communities have different requirements than research communities, one of which is transparency. In order to confidently use a product that can impact human lives and societal issues, the hazard and risk community needs to understand biases, assumptions, and the ranges of uncertainty used in developing a product. For this group of users, the value is in knowing the range of uncertainties in order to define risks. Thus, as this community expands, we will ask these new participants to respond to this review to gather new information about their data requirements.

\section{B. Use of Existing Soil Moisture Data}

The review shows the need for soil moisture observations among this interested community of respondents. Table III shows the use of simulated SMAP data from the mission, other sources of global remotely sensed soil moisture data from the soil moisture ocean salinity (SMOS) or the special sensor microwave/imager (SSM/I), or from ground observations from various sources. The majority of the respondents $(56 \%)$ have used ground observations in their work, with an additional $15 \%$ stating that they would use ground observations of soil moisture data if they had access to them. Seventy-five percent of the respondents were interested in conducting research on soil moisture and its relationship to their parameter of interest, $55 \%$ stated they would include the data in their system or process through assimilation technique, and 50\% said they would change their process to include direct observations or anomalies of soil moisture. This indicates that the desire to work with soil moisture observation data is of immediate interest to at least $50 \%$ of the community.

\section{Soil Moisture Data Requirements}

Questions 10 through 16 asked respondents what their needs were with regard to spatial resolution, spatial extent, latency, and temporal frequency (respondents were permitted to select more than one answer). These questions focused on exploring the needs of the community compared to what SMAP will provide. When asked what their specific application or analysis required, the respondents stated as follows.

- Spatial extent or coverage: 33\% stated they needed community-level data, 33\% county data, $53 \%$ state or regional data, and 58\% country-level data. In addition, $42 \%$ said that global data was necessary for their work.

- Spatial resolution: $63 \%$ stated that their needs were at the kilometer-scale and $51 \%$ that they needed hectare scale or smaller.

- Temporal frequency: $73 \%$ stated they needed data every day, where as $52 \%$ said weekly data was adequate.

- Latency: 36\% of respondents stated they needed data within 6 hours of acquisition, and 39\% within a day after acquisition.

- Prediction time scale: $56 \%$ stated that data that predicted environmental risk a week ahead would be useful for their analysis.

Broadly, SMAP will provide data that meet the needs expressed by this community. Table I shows the data product, latency and resolution planned by the mission. Users who need data more rapidly than is planned for the level 4 products can arrange to use the level 1 instrument data, which will be provided within 12 hours of acquisition. Although no product is planned to be produced within 6 hours, SMAP may work with NASA after launch to reduce latency times further to meet the needs of the community.

SMAP spatial extent is also too coarse for many users, who would prefer a $30-\mathrm{m}$ or $250-\mathrm{m}$ pixel size to the planned 3- or $6-\mathrm{km}$ resolution indicated in the planned SMAP data products. That being said, many users stated that they could use higher resolution data products together with SMAP data to increase their spatial specificity. As was found by Ross et al. (2009), the user community often requests higher spatial resolution data products than is possible to provide.

The results of the prediction time scale question was interesting, since the current SMAP mission does not plan to produce any soil moisture prediction products. The Level 4 integrated root zone soil moisture product has substantial temporal persistence, since once soils are saturated, it takes time for them to dry out, suggesting that predictions of soil moisture state could be produced with uncertainty estimates that may be useful to a substantial portion of the existing user community. 
TABLE III

Using SMap Test Data or Use a Proxy SoIl Moisture Dataset In Research or Activity

SMAP GloSim2 simulations SMOS-derived soil moisture data

$\mathrm{SSM} / \mathrm{I}$ soil moisture data

Model soil moisture -

GLDAS/NLDAS

Ground Observations

$\mathrm{Cal} / \mathrm{Val}$ field campaign data

\begin{tabular}{|cc|}
\hline $\begin{array}{c}\text { Use } \\
\text { currently }\end{array}$ & $\begin{array}{c}\text { Do not } \\
\text { have } \\
\text { access to }\end{array}$ \\
\hline $2 \%$ & $20 \%$ \\
& \\
$25 \%$ & $16 \%$ \\
$16 \%$ & $11 \%$ \\
& \\
$20 \%$ & $13 \%$ \\
$56 \%$ & $14 \%$ \\
$32 \%$ & $16 \%$ \\
\hline
\end{tabular}

\section{Soil Moisture Data Accuracy Needs}

The results show that $40 \%$ of respondents thought that an accuracy of $0.04 \mathrm{~m} 3 / \mathrm{m} 3$ per dekad was appropriate across all time scales, with fewer thinking lower accuracies were likely to be useful. Forty-three percent of the respondents stated that the current projection of the SMAP product accuracy will be sufficiently accurate for their application, and 33\% reported that this accuracy was adequate for historical information at the one, five and ten year time steps. As we moved further into more historical data (from 1 year to 10 years into the past), the accuracy requirement decreased. Thirty-three percent reported that a one year of historical information was adequate but a strong representation (35\%) of the respondents were unsure or did not know what their accuracy requirements would be. This confirms that users are unsure of their need for long time series and were uncertain about how accurate these historical products needed to be. Since few of the respondents use the existing satellite soil moisture products, there was little stated need for the continuation of these products and little was known about their uncertainties.

Notably, a similar percentage of the respondents were unsure or did not know what their accuracy requirements of their system or process, which is not surprising since there is limited satellite-derived soil moisture product in use today and $75 \%$ of the respondents did not currently use any satellite-derived soil moisture information (Table III). Although $56 \%$ of respondent use ground soil moisture observations, how the accuracy of these data relate to the stated accuracies of SMAP observations are unclear to respondents. Although both ground and satellite observations are stated in water fraction by volume (or $\mathrm{m} 3 / \mathrm{m} 3$ for SMAP), ground data is collected in known soil types with specific humus, sand, clay, and other soil components specified. Satellite data is, by necessity, aggregated over large spatial areas with heterogeneous soil types. Thus, it is important to translate how known accuracies will relate to the accuracies of SMAP observations and how the two will work together.

The impact of accuracy of ground measurements on an algorithm or estimation used for a particular decision is less clear, and research will need to be conducted on how satellite-derived observations can be used to simulate ground observations. Although soil moisture data is vital to most of the population decision-making and analysis, the accuracy requirements are unclear, likely due to the lack of satellite-derived soil moisture products in use today.

\begin{tabular}{cccc}
$\begin{array}{c}\text { Have not } \\
\text { used, but } \\
\text { would like } \\
\text { to }\end{array}$ & $\begin{array}{c}\text { Am not } \\
\text { familiar with }\end{array}$ & N/A & $\begin{array}{c}\text { Response } \\
\text { Count }\end{array}$ \\
$35 \%$ & $24 \%$ & $17 \%$ & 45 \\
$35 \%$ & $12 \%$ & $12 \%$ & 48 \\
$31 \%$ & $16 \%$ & $23 \%$ & 42 \\
& & & \\
$34 \%$ & $20 \%$ & $15 \%$ & 44 \\
$14 \%$ & $8 \%$ & $10 \%$ & 48 \\
$18 \%$ & $16 \%$ & $16 \%$ & 43 \\
\hline
\end{tabular}

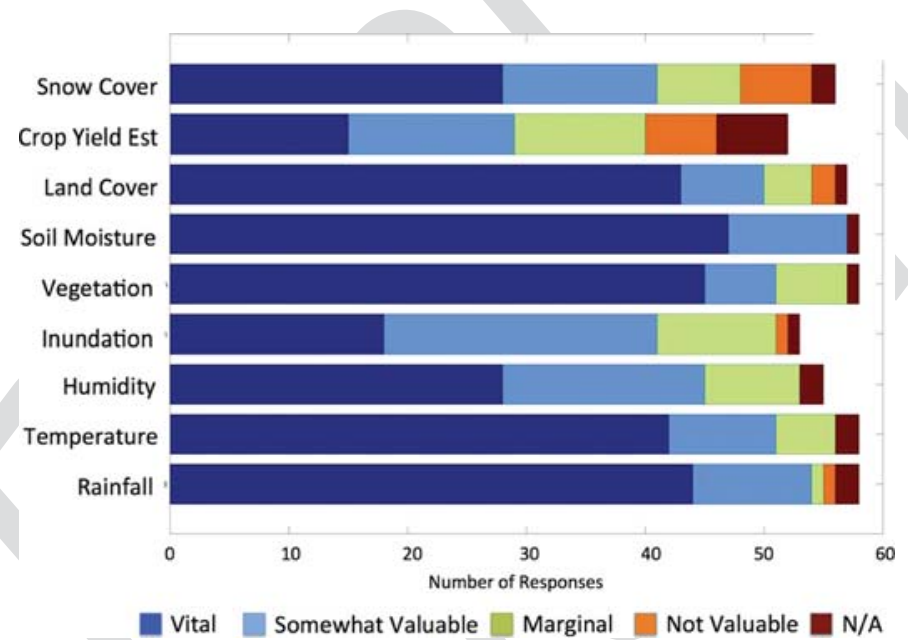

Fig. 3. Requirements for ancillary environmental variables for user community. N/A response was given when user was unsure of the use of the variable.

Fig. 3 shows how SMAP data products compare with the utility of other biophysical datasets that provide information on moisture availability. Forty-seven percent of respondents stated that soil moisture measurements would be vital to their application or analysis. When asked what the spatial extent that is needed for data, $58 \%$ of respondents stated they needed national-level data, $53 \%$ at the province or state level, and $46 \%$ at the region, ecosystem or multistate level.

\section{RESUltS OF SMAP FREEZE-THAW ASSESSMENT}

The SMAP mission will quantify the nature, extent, timing and duration of landscape seasonal freeze/thaw state transitions that are key to the estimation of terrestrial carbon sources and sinks. SMAP freeze/thaw state measurements will also contribute to understanding how ecosystems respond to and affect global environmental change, improving regional mapping and prediction of boreal-arctic ecosystem processes. Several questions in the survey sought to understand how these observations of freeze-thaw would be used. Forty percent of respondents said that the SMAP freeze/thaw product would be vital to their analysis, with an accuracy of within two days of the event. Several respondents said they needed subdaily accuracy. Having historical information to show change through time would be helpful, but those stating this was a requirement for their use of the data were only a small percentage of the total. Forty-one percent of the respondents stated that information 
about a thaw event occurring was important to their analysis as well as information that enabled an understanding of how that event related to past events. The spatial attributes of the information on freeze/thaw soil state was acceptable to $70 \%$ of the respondents, with $54 \%$ stating that the temporal frequency was adequate. Forty percent of the community stated that they did not need freeze-thaw products in their current analysis.

\section{SYNTHESIS OF FINDINGS}

The objective of this study was to solicit data requirements, accuracy needs and current understanding of the SMAP mission by the user community. We asked the SMAP user community what their accuracy needs were for spatial, temporal and latency characteristics of their data. From the respondents in this review, we found that the data to be provided by the SMAP mission did substantially meet the user community needs. Although there was a broad distribution of requirements stated, the SMAP mission fit within these requirements. For example, for spatial resolution, we had $19 \%$ of the respondents state they needed data from 10 - to $50-\mathrm{m}$ resolution, $17 \%$ from 50 - to $250-\mathrm{m}$ resolution, and $55 \%$ from 250 - to $9000-\mathrm{m}$ resolution. Although many would like higher spatial resolution than will be provided by SMAP, more than half agreed that the SMAP active/passive data was adequate for their uses and would be incorporated into their systems and processes for decision making.

The review provided opportunities for respondents to write comments about their specific needs that drove their spatial and temporal requirements. One respondent that worked in fire suppression stated that this community required daily information through the fire season, and monthly during the off-season. A shorter latency that allows the incorporation of the data into current fire risk products makes the data far more useful than if it is a day or more old. The USDA publishes weekly national and state-level reports of crop progress, crop conditions and soil moisture during the growing season [9]. These reports require accurate, spatially and spectrally detailed, timely satellite data and products of soil moisture, inundation, drought, etc., for monitoring and assessment of agriculture. Soil moisture is a critical element to multiple monitoring systems, from flood forecasting, fire potential, weather forecasting to agricultural monitoring, and the enthusiasm of users for the products is clear.

\section{A. SMAP Applications Program}

The overall goal of the SMAP Applications plan is to engage SMAP end-users and build broad support for SMAP applications through a transparent and inclusive process. The program seeks to promote the use of SMAP products to a community of end-users and decision makers that understand SMAP capabilities and are interested in using SMAP products in their application. One of the most effective ways we connect with users is through specific workshops and meetings that address the challenges and interests of defined user groups through two-way communication. Here we discuss the specific requirements and limitations for applying soil moisture data to systems and models such as urban models for water management, military operations and mobility, agriculture crop forecasting, flood analysis and insurance assessments. Only $26 \%$ of survey respondents have not attended one of these informational meetings. The facilitation of information from the use community back to the SMAP mission (through the use of this review, workshops, and communication directly with users) is designed to improve the advancement of future applications by providing fundamental knowledge to the mission. This review documents one of the many ways SMAP mission pre-launch application research is done and how it contributes to the broader mission goal.

\section{B. Limitations of This Work}

Eliciting requirements can be difficult due to problems of scope, understanding and changing requirements over time [10]. Many users who do not yet know about SMAP data won't be included in the assessment, affecting the scope of the results. As the user community grows, we will be able to better understand the extent of the impact of SMAP data on society. The results may also be affected by a lack of understanding of satellite-derived soil moisture data from SMAP and what it can and cannot do, which may reduce (or increase) the objectives of an application community when it ingests SMAP data. Finally, mission requirement changes over time will for example, affect reprocessing plans of SMAP mission post-launch or drive investments in reducing observed product latency. These issues limit the applicability of the results of this survey to the period before the sensor becomes operational. Therefore, we intend to conduct a follow up professional review one year after SMAP's launch to determine how the user community and their requirements have evolved after the sensor has begun delivering data.

\section{CONCLUSION}

The results of this review provided responses that showed the connection between the needs of the user community and the high quality soil moisture data planned to be provided by the mission. A broad diversity was found in the spatial, spectral and temporal needs of the user community. The existing plans of the SMAP mission to provide highly accurate, global 4- and 9-km soil moisture products meets $95 \%$ of the respondents their stated extent or coverage, $37 \%$ of spatial resolution, $63 \%$ of the temporal frequency, and $21 \%$ of the latency needs. To the extent that users knew their accuracy requirements, the stated accuracy of the soil moisture products will meet the majority of users' needs.

Opportunities for the SMAP mission to better address users' needs may lie in engaging with the scientific and operational community after launch to fund lower latency products in the way that the Earth Observing System (EOS) missions have done with the Land Atmosphere Near Real-time Capability for EOS (LANCE) system. The LANCE system has special processing elements, co-located with selected EOSDIS (Earth Observing System Data Information System) data centers and processing facilities, to process expedited data using optimized science algorithms that provide data in less than three hours. Although these near-real time products may have lower accuracy than standard science products, many users are willing to accept lower accuracy in exchange for timely access.

The review also identified gaps in the communities interested in using SMAP data by identified users that use soil moisture for research but are not connected to policy or decision making 
processes. It also highlighted the gap between users interested in SMAP products but unfamiliar with the mission, mission data, or simply did not have access to mission products. Having this information provides us with further insight on areas that need more information about SMAP mission products and the SMAP applications program.

This information further motivates the distribution of SMAP test products as well as other soil moisture data set (SMOS, $\mathrm{SSM} / \mathrm{I}$, simulation products, and ground observations) that will help increase familiarity and truly broaden and improve the field of applications. The review provided insight on the confidence and accuracies of combining satellite data with ground data. When we asked about using real time soil moisture versus historical soil moisture data, and going from using in situ data to gridded historical data, respondents' uncertainty increased.

There is still much to do in terms of mission applications but our growing success begins with the communication between scientists and users. Because we focus on the individual communication to better understand the uses of SMAP data, we continue to identify thematic needs and challenges that are communicated to the Mission scientists. Our individual communication with users evolves into focused sessions where we gather to discuss how to best address challenges and improve applications for SMAP data as we near launch.

\section{REFERENCES}

[1] G. Asrar, J. A. Kaye, and P. Morel, "NASA research strategy for earth system science: Climate component," Bull. Amer. Meteorol. Soc., vol. 82, pp. 1309-1329, 2001.

[2] NRC, "Earth Science and Applications from Space: A Midterm Assessment of NASA's Implementation of the Decadal Survey" Nat. Res. Council Space Policy Board, Washington, DC, USA, 2012.

[3] [update? N. Das, D. Entekhabi, and E. Njoku, "An algorithm for merging SMAP radiometer and radar data for high resolution soil moisture retrieval," IEEE Trans. Geosci. Remote Sens. E, 2011, to be published.

[4] M. E. Brown, S. Moran, V. Escobar, and D. Entekhabi, "Soil moisture active passive SMAP mission applications plan," NASA, Pasadena, CA, USA, 2011

[5] K. W. Ross, M. E. Brown, J. Verdin, and L. W. Underwood, "Review of FEWS NET biophysical monitoring requirements," Environ. Res. Lett., 2009, to be published.

[6] M. E. Brown, S. Moran, V. Escobar, D. Entekhabi, P. O’Neill, and E. Njoku, "The Soil Moisture Active Passive (SMAP) applications program," presented at the IEEE Int. Geosci. Remote Sens. Symp., Vancouver, Canada, 2011.

[7] K. W. Ross, M. E. Brown, J. P. Verdin, and L. W. Underwood, "Professional review to investigate FEWS NET requirements for Earth observation of precipitation and vegetation," Environ. Res. Lett., vol. 4, p. 024009, 2009.

[8] M. E. Brown, S. Moran, V. Escobar, and D. Entekhabi, "Soil moisture active passive SMAP mission applications plan," NASA Jet Propulsion Lab.y, Pasadena, CA, USA, 2011.
[9] J. D. Bolten, W. T. Crow, X. Zhan, C. A. Reynolds, and T. J. Jackson, "Assimilation of a satellite-based soil moisture product into a two-layer water balance model for a global crop production decision support system," in Data Assimilation for Atmospheric, Oceanic and Hydrologic Applications, S. K. Park and L. Xu, Eds. Berlin Heidelberg: Springer-Verlag, 2009, pp. 449-464.

[10] M. Christel and K. C. Kang, "Issues in requirements elicitation," Carnegie Mellon Univ., Software En. Inst., Pittsburgh, PA, USA, 1992

\section{1}

Molly E. Brown received the B.S. degree in biology from Tufts University, Medford, MA, USA, [AU: Year?] and then joined the Peace Corps, serving from 1992 to 1994 in Senegal, West Africa. She then received the M.A. degree and the Ph.D. degree in geography from the University of Maryland at College Park in 1999 and 2002, respectively.

In 2008, she published the monograph Famine Early Warning Systems and Remote Sensing Data (Springer-Verlag). Her work with FEWS NET has been the basis of a broader investigation of how earth science data is used for decision making in a variety of settings. In 2008, she joined NASA Goddard Space Flight Center, Greenbelt, MD, USA, as a civil servant in the Biospheric Sciences Laboratory. She is currently involved in projects that focus on expanding the use and utility of satellite remote sensing observations and earth science models in a variety of decision making contexts. She is currently working to implement applications programs for NASA's Soil Moisture Active Passive (SMAP) and the ICESat-2 missions, and is working with NASA's Carbon Monitoring System (CMS).

Vanessa M. Escobar received the B.S. degree in geology and chemistry from Sonoma State University, Rohnert Park, CA, USA, in 2000 and the M.S. degree in geology and water management policy from Arizona State University, Tempe, AZ, USA, in 2009.

Before attending undergraduate school, she joined the military, where she served for 14 years as a specialist in field hydrology and emergency operations. Before attending graduate school in 2005, she worked as a hydrology consultant in Arizona and specialized in well production development, water quality management, and ground water policy management from 2001 to 2004 . She was called to active duty with the Army for three years during Operation Iraqi Freedom and conducted hydrological research and operations for groundwater well drilling for Belad Iraq and worked as a liaison for the military in data communications and military deployment operations. She later attended graduate school at Arizona State University and worked as a Research Associate at the Global Institute for Sustainability (GIOS), where she coupled water balance models to Phoenix Arizona's water management policy to develop a scenarios-based analysis of the region's water supply's sensitivity to climate change and policy. She helped develop a prognostic modeling approach for the Phoenix Arizona Water Management area and continued her work within GIOS after graduation. She oined NASA Goddard, Greenbelt, MD, USA, as a contractor for Sigma Space in October 2010 and is actively involved in designing and implementing application programs for NASA's future earth observation missions [Soil Moisture Active Passive (SMAP, ICESat-2 missions, and NASA's Carbon Monitoring System (CMS)]. Her research is geared towards understanding the sensitivities of soil moisture data on flood models and applying that knowledge to operational applications. Her work is dedicated to connecting scientific data and models to areas where society will benefit from them most. She facilitates and translates discussions across scientific and political boundaries in the fields of hydrology, remote sensing, public health, water management, soil science, and water quality. 